\title{
The Prevalence of Diarrheal Disease in under Five Children and associated Risk Factors in Wolitta Soddo Town, Southern, Ethiopia
}

\author{
Kedir Addisu Alambo \\ Department of Public Health, MPH Program, Wolitta Soddo University (WSU), Wolitta Soddo, ETHIOPIA \\ (kediraddisu@gmail.com)
}

Copyright (C) 2014 (Kedir Addisu Alambo). This is an open access article distributed under the Creative Commons Attribution-NonCommercial-NoDerivatives 4.0 International License., which allowing others to download this work and share them with others as long as they credit us, but they can't change them in any way or use them commercially. In accordance of the Creative Commons Attribution License all Copyrights (C) 2014 are reserved for ABC Research Alert and the owner of the intellectual property (Kedir Addisu Alambo). All Copyright (C) 2014 are guarded by law and by $A B C$ Research Alert as a guardian.

\section{Abstract}

Though the relationship between environmental risk factors and the occurrence of diarrhea in children have been documented elsewhere, there are limited studies in Ethiopia in general and in Soddo Town in particular. The present study assessed the prevalence and associated risk factors of under-five children diarrheal disease

Community-based cross-sectional study was conducted in Soddo town, Southern Ethiopia. Nine hundred seventy (970) mothers/ care takers of index under-five children living in the households selected by systematic random sampling from Kebeles in the town constituted the study population. Data were collected using structured and pre-tested questionnaire, entered into a computer, edited and cleaned by using Epi info version 3.5.4 and analyzed using SPSS for windows version 16.0. Binary logistic regression model was used to calculate the Odds ratios and $95 \%$ confidence interval for the different risk factors and the level of significance was set at $P<0.05$.

Out of 970 sampled mother/caretaker-child pairs, 954 participated in the study and giving a response rate of $98.4 \%$. The mean ages of the respondents and the index children were 27.62 (+5.03SD) years and 26.41(+15.89 SD) months, respectively. Prevalence of diarrheal disease over a period of two weeks preceding the study was about $11 \%$. In the Bivariate analysis, a number of risk factors including monthly income less than five hundred birr and age of the child $(\mathrm{P}<0.05)$ appeared to be significantly associated with under-five childhood diarrheal disease and number of siblings under 5 years in a household, monthly income less than 500Birr and the age 12-23 months of the child were the only significant variables on multivariate analyses $(\mathrm{P}<0.05)$.

As diarrheal disease was major problem among under-five children in Soddo town. Appropriate intervention programs targeting Child birth spacing and improving the monthly income of households should be designed.

\section{Keywords}

Diarrhea, Associated factors, Under-five children, Ethiopia 


\section{Introduction}

Diarrheal diseases have long been established as a leading cause of morbidity and mortality throughout the world, where an estimated 3-5 billion diarrheal illnesses and 5-10 million diarrhea-related deaths occur annually among those living in Africa, Asia, and Latin Ameri$\mathrm{ca}[1]$. There are three clinical types of diarrhea: acute watery diarrhea- lasts several hours or days, acute bloody diarrhea also called dysentery, and persistent diarrhea that - lasts 14 days or longer [1].Children under five years of age are the most vulnerable, where 745 million to 1 billion episodes, and 3-4 million deaths occur each year (approximately 12,000 deaths per day) Consequently, diarrhea-related deaths are second only to respiratory infections as the greatest killer of children in less-developed countries [1].

The vast majority of these deaths from diarrhea are among children under-five years of age living in low- and middle- income countries [2].Currently, Ethiopia is ranked among the top five countries in the world in the absolute number of annual deaths in under-five children [1]. Hand washing with soap has been shown to reduce the risk of diarrhea by up to about a half. There is less documentation, however, on how governments and aid agencies can increase hand washing with soap [3].women who reported living in households with their main water supply as piped water and had homes with flush toilet are more likely to have children who experienced diarrhea, while women who used protected wells are less likely to have children who had diarrhea. Factors associated with diarrhea are age of child, maternal education, main source of water, toilet facility, area of residence, disposal of children's stool, and disposal of dirty water [4].

Diarrheal diseases are one of the top (major) leading causes of under-five morbidity, mortality and under nutrition in developing countries. In African countries including Ethiopia, each child on average suffers from five episodes of diarrhea per year while the two weeks prevalence ranges from 10 to $40 \%$ in different parts of Ethiopia. Diarrheal diseases have persistently been the first or the second causes of visits to health units in the country. In general, diarrhea alone contributes to $19 \%$ of the under five deaths globally, while $22.5 \%$ of hospitalization and up to $20 \%$ of all outpatient visits in children. Diarrheal death ratio, i.e number of deaths of children due to diarrhea over the total number of deaths of children due to any cause is $46 \%$. The dangers of diarrhea are related to dehydration and malnutrition while, dysentery is another important causes of death due to the fatal complications associated with it. The main objectives of control of diarrheal diseases (CDD) in Ethiopia are reduction of morbidity and mortality due to diarrheal disease in children under 5 years of age. The control and prevention can be achieved through effect curative, preventive, promotive and rehabilitative services [5].

Diarrheal diseases are a leading cause of childhood morbidity and mortality in developing countries where an estimated five million deaths occur each year in children under 5 years of age. Children under 5 years of age may experience as many as 5 episode of diarrhea per year, although a rate of 3-4 episodes is more common. Most of the diarrheal episode occurs in children in the first 2 years of life. In some areas young children spend $15-20 \%$ of their time with a diarrheal illness. Diarrheal episodes result in approximately 5 million deaths each year. About $80 \%$ of these deaths occur in children in the first 2 years of life. Most diarrheal illnesses are acute, lasting not more than 2 weeks; however, about $5 \%$ of these illnesses last longer [5]. 
These persistent diarrhea cases require care that is expensive and often ineffective, and they may cause as many as $25 \%$ of all diarrheal associated deaths. In addition to causing high rates of morbidity and mortality, diarrheal diseases are one of the main causes of childhood malnutrition. Also as many as $30 \%$ of pediatric beds in developing countries are occupied with children with diarrheal diseases. As a result, diarrheal diseases levy a very heavy burden on health facilities and national health budgets [5].

Globally, diarrhea is the third largest cause of morbidity and the sixth largest cause of mortality among population of all ages. A ten-year review of the global problem of diarrheal disease has shown that there are 1 billion episodes and 3 million deaths occurring each year among under-five children. It is one of the leading causes of morbidity and mortality in developing countries, especially among children under the age of five. In Africa, a child experiences five episodes of diarrhea per year, and 800,000 children die each year from diarrhea related dehydration [6].

Many health institutions attempt to improve the situation through training the mothers who were care givers for their under five children, expanding health education and community mobilization activities. However, these efforts were not based on systematic evidence into possible determinants of the prevailing practice. The present study was intended to contribute to bridging the information gap (sanitation, birth spacing etc) and subsequently improve the prevalence of diarrheal disease and associated factors in the city were the significance of this study.

\section{Method}

Study conducted in Soddo Town, Wolaita zone. It is located in SNNPR, Regional State of Southern part of the region at $381 \mathrm{~km}$ away from Addis Ababa. Soddo Town is the capital city of Wolaitta zone and a total population of 108,653. It has 3 sub- cities and 11 administrative Kebeles. The health service coverage of Wolaitta zone is $95 \%$ and Soddo town is $86 \%$. There are 2 hospital, 3 health centers, 11 health posts \& more than 15 private health institutions providing health services including diarrheal disease and associated factors in the town.

According to the 2012 zonal Central Statistics Agency (CSA), Soddo total population is estimated to 105,591 and with about 21,549 households and is estimated to be 108,653 total population and 22,174 households when projected for 2013 by considering $2.9 \%$ as rate of natural increase for SNNP region. The total number of under-five children in the town was estimated to be 16,950 at the end of 2013 based on the assumption that $15.6 \%$ of the total population is under-five children. A community based cross-sectional study was conducted in Soddo town from Dec 15-Jan 2, 2013/2014

The source population is all mothers/ care givers-under-five children living in the town and study population was mothers with children aged less than five years living in the selected households sampled and from whom data was collected. Mothers with their child aged less than five years willing to participate in the selected Kebeles and households were included and Mothers/ care givers of under-five children who had other health problem, critically ill and those who did not permanently live in the town was excluded.

Multi-stage sampling procedure was employed, first by selecting five Kebeles from the eleven using lottery method. Then, all households in the selected Kebeles was registered through a house-to-house census by ten trained enumerators and a total of 9284householdsof which 
2371 from Fana, 1928 from Dill-betgle, 1744 from wadu, 1639 from selam and 1602 from keraKebeles was listed and at the time of survey, the households with under five children were identified and registered sequentially and give identification number in order. Households were allocated to each Keble proportional to size. Then, systematic sampling (every $10^{\text {th }}$ households) from the households with under- five children identified and registered sequentially by survey in the Kebeles was included for the study. The selected households with under five children in selected keble were (1813, 1253, 1334, 1474 and 1225).

Systematic random sampling method was used (every $10^{\text {th }} \mathrm{HH}$ ) to identify eligible households (Lottery methods) was used to select the first $\mathrm{HH}$ from the first ten households and number 5 was drawn $(5,15,25 \ldots .$.$) In case, where there were more than one under-five children in the same$ household, only one child was selected by lottery method to collect information on child's health characteristics. Also In case, where there were more than one Mothers/ care givers of under-five children were in the same households, only one mothers/care givers was selected by lottery methods to collect information on child's health characteristics.

To determine sample size, SNNPR, regional two-week period prevalence of diarrhea (16.4\%) among under-five children was taken from the recent report of the Ethiopian Demographic and Health Survey of 2011 to calculate the sample size. Using the assumptions of design effect 1.5, desired precision $\mathbf{3 \%}$, confidence level $\mathbf{9 5 \%}$ and an anticipated non-response $\mathbf{1 0 \%}$, to determine sample size, from the source population, standard formula was used based on the SNNPR, regional prevalence of $16.4 \%$ diarrheal disease in under-five children, $n=z_{1 a / 2}^{2} p(1-p) / d^{2}$ where, $\mathrm{n}=$ sample size, $\mathrm{d}=$ desired precision $3 \%=(0.03), \mathrm{z}=$ standard normal distribution value at confidence level $95 \%=(1.96)^{2,} \mathrm{p}=$ prevalence of diarrheal disease $=16.4 \%, \varepsilon$ (epsilon) $=$ assumptions of design effect $=1.5$, the calculated sample size was $\mathbf{9 7 0 .}$

To determine the sample size for risk factors associated with diarrheal disease is calculated using EPI-Info sample size calculation software version 3.5.1 by assuming of recent study conducted in different study area in Ethiopia and other countries, the calculated sample size was (150,322 and 352), so the largest sample size was taken for the study (970).

10th Grade completed and above ten data collectors and two supervisors from Soddo town who were fluent in Amharic and Wolaitgna was trained on data collection instruments, field methods, inclusion and exclusion criteria, record keeping and flow of records to the data entry.

Ten percent of the questionnaire was pre-tested in another Keble with the same level in every aspects of basic infrastructure and socio-demographic characteristics in the study area. Data collectors were assigned based on population size of each Kebeles. Data collectors were performed house-to-house visit and interviewed the mothers/ care takers of under-five children health characteristics. Then data on Diarrhea disease and associated factors were collected from each of the individual child by using a structured questionnaire which was translated from English languages in to Amharic and who was by fluent speaker of both languages to ensure its validity and consistency and the supervisors was fully responsible to lead and handle the whole session of data collection process, and correct any problem along with the principal investigator.

The occurrence of diarrheal disease status in the past two weeks were dependent variable and Income of a family, Maternal age, Age of child, Housing condition, Family size, Maternal 
education, the availability of latrine and utilization, Hand washing facility, Types of water source, Distance from the drinking water source (time spent to-and-from the source), Amount of daily water consumption, Presence or absence of pit hole cover, Waste disposal method, Housing floor, latrine and compound cleanliness were independent variable.

Data entry and cleaning were made using EPI info Version 3.5.4 statistical software and analyzed using SPSS software package version 16.0. Descriptive statistics such as frequency distribution, mean, percentages, $\mathrm{p}$-values of less than 0.05 and odds ratio for statistical significant tests were employed for the analysis. Binary logistic regression analysis was carried out to assess the relative importance of the explanatory/exposure variables on the dependent/outcome variable. To avoid an excessive number of variables and unstable estimates in the subsequent model, only variables reached a p-value less than 0.2 were kept in the subsequent analyses.

Ethical clearance was obtained from the Institutional Review Board (IRB) of the WSU. Then the concerned officials in the zone and town at each level were communicated through formal letters from the School of public health WSU MPH program. Informed verbal consent was obtained from the mothers of the children. Interview was conducted privately and then confidentiality of information was ensured through records were coded and accessed only by research team. Children who were found to be sick during the visits were advised to visit the nearby health Institution immediately.

\section{Results}

A total of 970 households with at least one under-five children were planned to participate in the study, out of which 954 were enrolled making a response rate of 98.4\%. Almost all respondents were biological mothers (98.4\%), Protestant 645(67.6\%) and Orthodox 266 (27.9\%) by religion, Wolaita $792(83 \%)$ by ethnic group, married (95.2\%) and housewives (60.6\%), most had attended formal education (70.9\%) and were from urban. 397 of the mothers/caretakers $(41.6 \%)$ were age between 26-30 years of while the majority, $81(8.5 \%)$ were in the age $\leq 20$ years and $284(29.8 \%)$ were with the age of $21-25,139(14.6 \%)$ were the age of 31-35 and 53(5.6\%) of mothers were above 35 years. The mean ages of the respondents and the index children were $27.62( \pm 5.03 \mathrm{SD})$ years and $26.41( \pm 15.89 \mathrm{SD})$ months, respectively. The mean family size of the study population was $5.2( \pm 1.8 \mathrm{SD})$ persons. There was one under-five child in $781(81.9 \%)$ households, and $173(18.1 \%)$ households had two or more under-five children. There was slightly more male (58.5\%) than female children (41.5\%).104 had diarrhea two weeks before the interview, provided a prevalence of $\mathbf{1 1 \%}$. Children in the age group 12 - 23 months had the highest prevalence of diarrhea $(\mathbf{1 8 . 5 \%})(\mathrm{p}=0.002)$ Table-1:

The majority, 620 (65\%) living in houses floor made of cement and 610 (63.9\%) households used drinking water from Improved sources which is mainly piped water. 641 (67.2\%) claimed to have spent 15 minutes or less time walk to fetch water.815 (87.3\%) of the study households had privately owned latrine and 119 had shared latrine facility and $16(1.7 \%)$ did not have the latrine facility. Out of (938) those who had latrine, 899(95.8\%), $12(1.3 \%)$ and $27(2.9 \%)$ households had simple pit latrine, ventilated and improved pit latrine and pour-flush latrine, respectively. Out of 938 households with latrine facility, the majority were observed that the pit hole do not have a cover 592 (63.2\%). With regard to waste disposal facility, 66(6.9\%), 443(46.4\%) and 445(46.7\%) reported to have disposed their waste in open field, garbage bin and pit/burning respectively Table-2: 
Multivariate analyses were carried out to identify the risk factors associated with diarrhea. In the binary logistic regression model, diarrhea was in- dependently associated with number of siblings under 5 years in a household is greater than one, monthly income less than 500Birr and age of the child. More specifically, The odds of diarrhea was 1.7 times higher in children from the households with two or more siblings compared to children in the house-holds with only one sibling $(\mathbf{A O R}=\mathbf{1 . 7}, \mathbf{9 5} \% \mathbf{C I}(\mathbf{1 . 0 1}, \mathbf{2 . 8 9})$. Children in the age group 12-23 month had 2.33 times higher odds of having diarrhea compared to children in the age group above 35 month $(\mathrm{OR}=\mathbf{2 . 3 3}, \mathbf{9 5 \%} \mathrm{CI}(\mathbf{1 . 3 5}, \mathbf{4 . 0 2})$ and the odds of diarrhea was 1.9 times higher in children from the house hold monthly income less than 500Birrcompared to children in households with monthly income 500Birr and more (AOR=1.9, 95\% CI (1.05, 3.43).

Multivariate analyses were also carried out to identify the risk factors not significantly associated with diarrhea. In the binary logistic regression model, diarrhea was not significantly associated with education of mother, family size, source of water, latrine pit hole cover, latrine ownership, feces seen at hole, feces seen at compound, waste disposal and presence or absence of hand washing facility Table-3:

\section{Tables and Figures}

Table-1: Socio-economic and demographic characteristics of the respondents, Sodo town 2014

\begin{tabular}{|l|l|c|c|}
\hline Variables & Response category & Frequency(954) & \% \\
\hline Sex of Child & Male & 558 & 58.5 \\
\cline { 2 - 4 } & Female & 396 & 41.5 \\
\hline \multirow{5}{*}{ Age of child in month } & $0-5$ & 106 & 11.1 \\
\cline { 2 - 4 } & $6-11$ & 83 & 8.7 \\
\cline { 2 - 4 } & $12-23$ & 184 & 19.3 \\
\cline { 2 - 4 } & $24-35$ & 201 & 21.1 \\
\cline { 2 - 4 } & $>35$ & 380 & 39.8 \\
\hline \multirow{5}{*}{ Religion } & Wolaita & 792 & 83 \\
\cline { 2 - 4 } & Others & 162 & 17 \\
\hline Education of mothers/ caregivers & Protestant & 645 & 67.6 \\
\cline { 2 - 4 } & Orthodox & 266 & 27.9 \\
\cline { 2 - 4 } & Others & 43 & 4.5 \\
\cline { 2 - 4 } & No formal education & 278 & 29.1 \\
\cline { 2 - 4 } & Primary & 434 & 45.5 \\
\cline { 2 - 4 } & Secondary & 55 & 5.8 \\
\cline { 2 - 4 } & College and above & 187 & 19.6 \\
\hline Family size & $\leq 4$ & 388 & 40.7 \\
\cline { 2 - 4 } & $>4$ & 566 & 59.3 \\
\hline Number of $<$ children & One & 781 & 81.9 \\
\cline { 2 - 4 } & Two and above & 173 & 18.1 \\
\hline Occupation of mother/care givers & House wife & 578 & 60.6 \\
\cline { 2 - 4 } & Civil servants & 172 & 18.0 \\
\cline { 2 - 4 } & Merchants & 167 & 17.5 \\
\cline { 2 - 4 } & Others & 37 & 3.9 \\
\hline \multirow{5}{*}{ Monthly in come } & $<500$ & 108 & 11.3 \\
\cline { 2 - 4 } & $500-1000$ & 130 & 13.6 \\
\cline { 2 - 4 } & $>1000$ & 413 & 43.3 \\
\cline { 2 - 4 } & I don't know & 303 & 31.8 \\
\hline & & & \\
\hline
\end{tabular}


Table-2: Environmental characteristics of the study households in Sodo town, 2014

\begin{tabular}{|c|c|c|c|}
\hline Variables & Response category & Frequency $(n=954)$ & $\%$ \\
\hline \multirow[t]{3}{*}{ Housing floor material } & Mud & 305 & 32 \\
\hline & Wood & 29 & 3 \\
\hline & Cement & 620 & 65 \\
\hline \multirow[t]{5}{*}{ Drinking water source } & Protected Spring water & 160 & 16.8 \\
\hline & Unprotected spring water & 52 & 5.5 \\
\hline & Private Piped tap water & 409 & 42.9 \\
\hline & Public Stand pipe/tap & 201 & 21.1 \\
\hline & Unprotected dug well & 132 & 13.8 \\
\hline \multirow[t]{3}{*}{ Daily water consumption (in liters) } & $<20$ & 174 & 18.2 \\
\hline & $20-30$ & 196 & 20.5 \\
\hline & $>30$ & 584 & 61.2 \\
\hline \multirow{4}{*}{ Type of latrine } & Simple pit latrine & 899 & 95.8 \\
\hline & Ventilated improved pit latrine & 27 & 2.9 \\
\hline & Pour-flush latrine & 12 & 1.3 \\
\hline & No latrine & 16 & 1.7 \\
\hline \multirow[t]{2}{*}{ Latrine ownership } & Privately owned & 819 & 87.3 \\
\hline & Shared & 119 & 12.7 \\
\hline \multirow[t]{2}{*}{ Latrine pit-hole cover } & Yes & 345 & 36.8 \\
\hline & No & 592 & 63.2 \\
\hline \multirow{2}{*}{$\begin{array}{l}\text { Feces seen around the pit- } \\
\text { hole/slab/floor of latrine }\end{array}$} & Yes & 363 & 38.7 \\
\hline & No & 575 & 61.3 \\
\hline \multirow[t]{2}{*}{ Feces seen in the compound } & Yes & 94 & 10 \\
\hline & No & 844 & 90 \\
\hline \multirow[t]{3}{*}{ Waste disposal method } & Pit/Burning & 445 & 46.7 \\
\hline & Garbage bin & 443 & 46.4 \\
\hline & Open field & 66 & 6.9 \\
\hline \multirow{2}{*}{ Hand washing facility } & Yes & 361 & 37.8 \\
\hline & No & 593 & 62.2 \\
\hline
\end{tabular}

Table-3: Bivariate and Multivariate analysis of risk factors of diarrhea among children under 5 years of age in Sodo Town, Southern Ethiopia, 2014

\begin{tabular}{|c|c|c|c|c|}
\hline \multirow[b]{2}{*}{ Variable } & \multicolumn{2}{|c|}{ Diarrheal disease (DD) } & \multicolumn{2}{|c|}{ Odds Ratio $\quad(95 \% \mathrm{CI})$} \\
\hline & Yes $(\%)$ & No $(\%)$ & Bivariate (COR) & Multivariate (AOR) \\
\hline \multicolumn{5}{|l|}{ Age of child in month } \\
\hline $0-5$ & $9(8.6)$ & 97(91.4) & $1.01(0.47,2.19)$ & $1.07(0.49,2.36)$ \\
\hline 6-11 & $11(13.3)$ & $72(86.7)$ & $1.66(0.8,3.45)$ & $1.61(0.75,3.45)$ \\
\hline $12-23$ & $34(18.5)$ & $150(81.5)$ & $2.47(1.47,4.14) * * *$ & $2.33(1.35,4.02)^{* *}$ \\
\hline 24-35 & $18(9)$ & 183(91) & $1.07(0.58,1.96)$ & $1.14(0.61,2.14)$ \\
\hline$>35^{+}$ & $32(8.4)$ & $348(91.6)$ & 1.00 & 1.00 \\
\hline \multicolumn{5}{|l|}{ Number of $<5$ children } \\
\hline one $^{+}$ & $78(10)$ & $703(90)$ & 1.00 & 1.00 \\
\hline Two and above & $26(15)$ & $147(85)$ & $1.6(0.99,2.57)$ & $1.7(1.01,2.89)^{*}$ \\
\hline \multicolumn{5}{|l|}{ Monthly Income } \\
\hline$<500 B i r r$ & $20(18.5)$ & $88(81.5)$ & $2.1(1.22,3.62)^{* *}$ & $1.9(1.05,3.43)^{*}$ \\
\hline 500-1,000 Birr & $14(10.8)$ & $116(89.2)$ & $1.12(0.61,2.04)$ & $0.98(0.51,1.89)$ \\
\hline >1,000 Birr $^{+}$ & 70(9.8) & $646(90.2)$ & 1.00 & 1.00 \\
\hline \multicolumn{5}{|l|}{ Source of water } \\
\hline Improved $^{+}$ & $59(9.7)$ & 551(90.3) & 1.00 & 1.00 \\
\hline Unimproved & $45(13.1)$ & $299(86.9)$ & $1.41(0.93,2.13)$ & $1.2(0.76,1.9)$ \\
\hline Latrine pit hole cover & & & & \\
\hline
\end{tabular}


ABC Research Alert, Valume 3, № 2/2015

\begin{tabular}{|c|c|c|c|c|}
\hline Yes+ & $33(9.6)$ & $312(90.4)$ & 1.00 & 1.00 \\
\hline No & $67(11.3)$ & $524(88.7)$ & $0.83(0.54,1.29)$ & $0.94(0.56,1.56)$ \\
\hline Latrine ownership $^{\text {private }}{ }^{+}$ & $86(10.5)$ & $733(89.5)$ & 1.00 & 1.00 \\
\hline Shared & $14(11.8)$ & $105(88.2)$ & $0.88(0.48,1.6)$ & $1.11(0.58,2.10)$ \\
\hline Feces seen at compound & & & & \\
\hline Yes & $15(16)$ & $79(84)$ & $0.59(0.33,1.07)$ & $0.7(0.36,1.35)$ \\
\hline No $^{+}$ & $85(10.1)$ & $759(89.9)$ & 1.00 & 1.00 \\
\hline Hand washing facility & & & & 1.00 \\
\hline yes & & & & \\
\hline No & $33(9.1)$ & $328(90.9)$ & 1.00 & $0.82(0.49,1.38)$ \\
\hline Statistically significant at $\mathrm{P}<0.05, \quad * *$ at $\mathrm{P}<0.01$ and $* * *$ at $\mathrm{P}<0.001,{ }^{+}$Reference group
\end{tabular}

\section{Discussion}

This study investigated the prevalence, socio- economic, environmental risk factors of diarrhea disease in children under five years old in southern Ethiopia. The two-week prevalence of diarrhea among the children was $\mathbf{1 1 \%}$. The occurrence of diarrhea was associated with aged 12- 23 month, presence of two or more children under-five years old in the household and monthly income less than 500 Birr.

The two-week period of diarrhea occurrence used as a criterion in my study is comparable with studies conducted in Keffa Sheka Zone Western part of Southern Ethiopia its two week period prevalence is $\mathbf{1 5 \%}$ [7], in VietNam was 11.3\%[8] and In Bangladesh was 8.1\% [8]. Such high rate of childhood diarrhea, despite considerable improvements in water sources and sanitation facilities, indicates the need for more attention.

In this study, diarrhea was significantly associated with the presence of two or more under five children in the family. This is in agreement with a study done in Kerssa district Eastren Ethiopia [9] and Vietnam [8]. Other study done In Eretria [10] also indicated that number of children born was a predictor of diarrhea among under-five children. This might be due to the incapability of the mothers/caregiver to care for a large number of children. It is possible to suggest that child birth spacing might have a positive influence on prevention of diarrhea. But the study done in the Derash district contradicts this. There might be differences in maternal attention, general living condition and difference in study design that could explain the disparate finding. It is known that as the number of children in a family becomes larger, there may be crowding which deteriorates the hygiene condition, which in turn increases the chance of contact with pathogens. There may also be competition for the mother's attention and other resources.

Another Study showed that the open disposal of waste around the house was an independent risk factor for diarrhea. The simple explanation might be that inappropriate disposal of waste provides breeding site for insects, which may carry diarrhea pathogens from the waste to water and food [2] and importance of hand washing in reducing the occurrence of childhood diarrhea [3] However, monitoring correct hand washing behavior at critical times is challenging. The availability of water and soap in places of hand washing as indicator of hand washing behavior [3]. But, In this study, there was no a significant association between the availability of hand washing facility and waste disposal system with childhood diarrhea. This might be also the difference of study area like residence. This could be also attributed to the fact that the lack of access to water and sanitation facilities in the rural areas was more than in the urban areas [9]. 
This study showed that diarrhea was significantly associated with children in the age groups 12 - 23 months compared to children aged above 35 months. This finding is in agreement with other studies [8]. This may be the risk of acquiring diarrhea increases at the time the child start moving around the house and receiving food other than breast milk.

This is also the time of stopping breast milk for most of under-five children, when breast feeding stops, infants are exposed to food borne germs and loss the protection of breast milk's anti-infective properties. The peak prevalence of diarrhea at the age of $6-11$ months $\mathbf{( 1 3 \% )}$ and 12-23 months $\mathbf{( 1 8 . 5 \% )}$ can be explained by the introduction of contaminated weaning foods [9]. In addition, crawling starts at this age and the risk of ingesting contaminated materials may cause diarrhea. The risk of diarrhea decreases subsequently after 23 month; this is probably because the children begin to develop immunity to pathogens after repeated exposure [9]. In this study the households with monthly income less than 500 Birr were significantly associated with diarrheal disease in under five children. This is consistent with the study done in Eretria, but contradicts with other study done in different area $[2, \mathbf{6}, \mathbf{9}]$

Strengthen of this study was two weeks occurrence of diarrhea was carried out through employing a very few question followed by the employment of a well experienced field team to interview and Moreover those who had diarrhea at the time of data collection were linked to the ongoing near health center for further investigation and treatment. This study didn't investigate for how many days they delay when their child had diarrhea from first visit to the health institutions and what was the outcome if they visit this conditions might limit the study.

\section{Conclusion}

In this study the prevalence of diarrheal disease is low where compared with another study. The factors that were significant association with childhood diarrhea in this study were number of under five children in household greater than one, house hold monthly income less than 500Birr and age of children 12-23 months.

In conclusion, childhood diarrhea remains an important health concern in the study community. Occurrence of diarrhea could be decreased by interventions aimed to improve sanitation, hygiene, economic status of the households and child birth spacing.

The Promotion of health education for reproductive age groups for child birth spacing, it might have a positive influence on prevention of diarrheal disease, Food hygiene and general sanitation, Empower and mobilize the community or households to improve socioeconomic status were highly recommended and further research: in the area is also recommended Authors' contributions: Kedir Addisu, conceived the idea and designed the study, coordinated data collection, performed analysis and obtained funding, interpretation of data and drafted the manuscript and critical review, instrument development and manuscript writing

\section{Acknowledgments}

I gratefully acknowledge the University of Wolaitta Soddo /WSU for giving me this marvelous MPH training opportunity and the Library and Internet center for their assistance in searching the necessary literature for developing this thesis. I wish to acknowledge Soddo Town health office for its support and collaboration throughout this project. I specifically would like to thank field data collectors and supervisors for their hard work in making this study possible. Finally, I would like to thank my family for their all rounded support, care and understanding. 


\section{References}

1. Kebede S, Fisihatsion T, Tesfaye W, Asres T, Kemal N, Dubale T, Tadios Y, Anmaw T, Mekonen W, and Joel T,1995. Epidemiological Health Survey of a Rural Peasant Association in Southwestern Ethiopia, Jimma Institute of health science

2. Godana W, Mengiste B, Environmental Factors Associated With Acute Diarrhea among Children Under Five Years of Age in Derashe District, Southern Ethiopia, Science Journal of public Health, Vol. 1, No. 3, 2013

3. International rescue committee, understanding hand washing behavior in Kenya, Thailand, Ethiopia 2011

4. Siziya S, muula A, Rudatsikira E, Diarrheal disease And Acute Respiratory Infections Prevalence And Risk Factors Among Under-Five Children, In Iraq, 2000

5. Belachew T, Jira C, Faris K, Mekete G, Asres T, and Aragaw H, Diarrheal Disease for the Ethiopian Health Center Team, Jimma University In collaboration with the Ethiopia Public Health Training Initiative and the Carter Center, in 2001

6. Regassa G, Birke W, Deboch B, Belachew T, Environmental determinants of diarrhea among under-five children in nekemte town, western Ethiopia 2008

7. Teklemariam S, Getaneh T, Bekele F. Environmental determinants of diarrhea morbidity in under-five children. Keffa-Sheka Zone Southwest Ethiopia. Ethiop Med J, 2000; 38(1): 27-34

8. Mrs Nida Rohmawati. Factors associated with diarrhea among under five years old children in banten province Indonesia .A secondary analysis of Indonesia maternal socio economic survey 2007 and basic health research 2007

9. Bezatu M, Yemane B, Alemayehu W. Prevalence of diarrhea and associated risk factors among children under-five years of age in kersa district, Eastern Ethiopia, 2011, vol.3, No.7, 446-453 (2013)

10. Bui Viet Hung, The most common causes and risk factors for diarrhea among children less than five years of age admitted to Dong Anh Hospital, Hanoi, Northern Vietnam, may 2006

11. Davidson H. Hamer, M.D. ARCH Project Scientist Jonathon Simon, M.P.H.ARCH Project Director Donald Thea, M.D., M.Sc.ARCH Project Scientist Gerald T. Keusch, M.D.ARCH Scientific Director Child Health Research Project Special Report, in sub Saharan Africa, April 1998

12. Ethiopia public health association: The Ethiopian journal of Health Development 2012

13. Patrick Kelly Habib Khanfir Patricia H. David Michelle Arata and Eckhard F. Kleinau Environmental and Behavioral Risk Factors for Diarrheal Diseases in Childhood: A Survey in Two Towns in Morocco September 1999

14. Ethiopian public health Association Annual report 2011/2012

15. Rishi P. Mediratta, Feleke A, R. Bradley Sack, Risk Factors and Case Management of Acute Diarrhea in North Gondar Zone, Ethiopia June 2010

16. Christopher S Yilgwan, SN Okolo, Prevalence of diarrhea disease and risk factors in Jos University Teaching Hospital, Nigeria Department of Paediatrics, Jos University Teaching Hospital, PMB 2076, Jos, Nigeria 2012 | Volume: 11 | Issue: 4 | Page: 217-221.

17. Annual report of soddo town health office (health centers) 2013

18. Annual report of woliyta zone health desk 2013

19. Recent report of the Ethiopian Demographic and Health Survey of 2011

20. Federal ministry of health : Health sector Development program 4-2010/11-2014/15 
21. Ethiopian public health association,13th world congress on public health 23-27 April,2012,United nations conference center (UNCC)

22. Ethiopian public health association Proceeding the 22ndAnnual conference October 311st to November 3, 2011, United nations conference center (UNCC)

23. Remidius Kamuhabwa Kakulu, diarrhea among under five children and household water treatment and safe storage factors in mkuranga district Tanzania Muhimbili University of Health and Allied Sciences November, 2012

24. United state Agency international Development, family Health Inter nation, survey on diarrheal disease in under five children 2004

25. United States Office of Science and Technology EPA-823-R-99-011 Environmental Protection Office of Water August 1999 Agency Washington Giardia: Risk for Infants and Children under five years

26. The Last Ten Kilometers Project, 2009. Baseline Household Health Survey: Amhara, Oromiya, SNNP and Tigray. JSI Research \& Training, Inc., Addis Ababa, Ethiopia

27. Byomkesh Manna, Dilruba Nasrin, Suman Kanungo, Subhasis Roy, Determinants of Health Care Seeking for Diarrheal Illness in Young Children in Urban Slums of Kolkata, by The American Society of Tropical Medicine and Hygiene 2013 